Research Article

\title{
Use of Rubber Mat to Improve Deformation Behaviors of Ballastless Tracks Laid on Bridges
}

\author{
Weiqi Zheng $(\mathbb{D}$, Xingwang Sheng $(\mathbb{D}$, Hongqiang He, Hongyi Xu, and Ying Yang
}

School of Civil Engineering, Central South University, Changsha 410075, China

Correspondence should be addressed to Xingwang Sheng; shengxingwang@163.com

Received 17 May 2020; Revised 13 July 2020; Accepted 31 July 2020; Published 17 August 2020

Academic Editor: Fan Gu

Copyright (c) 2020 Weiqi Zheng et al. This is an open access article distributed under the Creative Commons Attribution License, which permits unrestricted use, distribution, and reproduction in any medium, provided the original work is properly cited.

\begin{abstract}
The deformation behaviors of ballastless tracks have an important influence on their service performance. In this work, rubber mats commonly used in metro traffic were employed in ballastless tracks laid on bridges to improve their deformation behaviors. In order to research the effect of rubber mat for deformation behaviors, a series of static loading tests were carried out based on two full-scale ballastless tracks with different types of isolation layers. Main conclusion include that, for ballastless track with geotextile isolation layers, gaps and voids are formed at interlayers with the increasing static load. However, for ballastless track with rubber mat isolation layer, the maximum tensile deformation in the thickness direction unexceeds the precompression of rubber mat under the deadweight of its upper structures. Interlayer gaps and voids can be eliminated due to the precompression of rubber mat. Besides, the rubber mat isolation layer is still in the linear elasticity stage under the routine service condition, and the interlayer behaviors of the ballastless tracks perform well. It is a feasible way to use a rubber mat isolation layer to improve the deformation behaviors of ballastless tracks laid on bridges.
\end{abstract}

\section{Introduction}

High-speed railway was developed rapidly in recent years; as a typical track structural pattern, ballastless tracks were widely applied in high-speed railways, especially in China [1]. Certainly, higher requirements are put forward for ballastless tracks with the development of high-speed railway technologies [2-5]. A traditional ballastless track generally consists of rails, track slab, self-compacting concrete layer or cement asphalt mortar layer, isolation layer, and base plate (Figure 1). Nowadays, several modifications of traditional ballastless tracks have been developed to obtain a higher bearing capacity system while increasing its durability [6]. As a kind of railway elastic elements, an isolation layer coordinated the deformation between lower structures and ballastless tracks and achieved isolation for facilitating maintenance [7]. Reasonable adjustment of the isolation layer is a way to improve the structural performance of ballastless tracks. The commonly used isolation layers in ballastless tracks included EPDM isolation layer (ethylene propylene diene monomer), geotextile isolation layer, and so on (Figure 2) $[8,9]$. Due to lack of thickness, it is difficult for these isolation layers to compress and their elastic properties are not prominent. They mainly play the role of interlayer isolation and have no regulating effect on interlayer deformations. It is of particular importance to identify the effect of using new isolation layers to improve deformation behaviors of ballastless tracks laid on bridges.

With the increase in the rail freight traffic and the train running speed, many countries have incorporated some elastic elements into their railway systems as the standard practice [10-12]. Rubber mats are essential in ballasted tracks at some regions such as tunnels and bridges where the elastic components are necessarily required in the railway structures to reduce the stress on the substructures as well as the vibration and noise levels due to the deformation capacity and mechanical energy dissipation of rubber material $[13,14]$. Primarily being applied in ballasted tracks, rubber subballasted mats have been growing as a feasible and effective solution to guarantee the reliable properties of ballasted tracks [15-17]. In this regard, it is an attempt to use the rubber mats as isolation layers in ballastless tracks laid on 


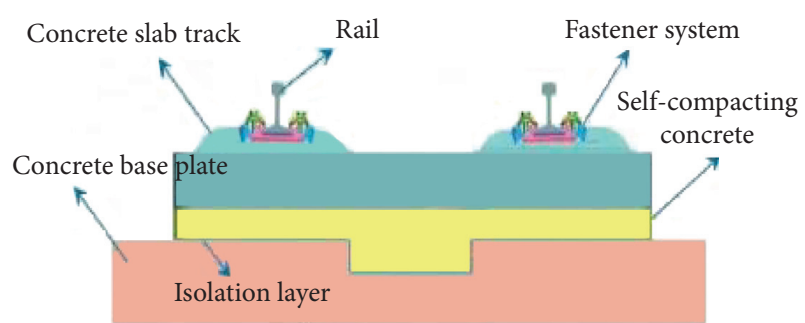

Figure 1: The structures of a traditional ballastless track.

bridges to improve their deformation behaviors. The reasonable arrangement of the isolation interlayer of the ballastless tracks can reduce the related defects such as gaps and voids at interlayers. It is worthwhile to take the rubber mats commonly used in metro traffic transit as the isolation layers in ballastless tracks to improve their deformation behaviors (Figure 3).

In this research, a type of rubber mat is employed in ballastless tracks to achieve interlayer isolation and deformation adjustment of ballastless tracks under routine service conditions. In this context, a series of full-scale laboratory tests are carried out to research the deformation characteristics of the ballastless tracks laid on bridges. Furthermore, the measures to reduce inconsistency of interlayer deformations are explored.

\section{Full-Scale Laboratory Tests}

2.1. Test Objects and Materials. In this research, two groups of full-scale static loading tests were conducted to demonstrate the feasibility of using rubber mats to improve ballastless tracks behaviors. The two full-scale ballastless tracks were poured on the concrete bridge deck of a simply supported box girder in a laboratory (Figure 4). The structure of the simply supported box girder and the location of these ballastless tracks laid on the simply supported box girder are shown in Figure 5, and more information can be found in [18].

The structural details of ballastless tracks used in this work are listed in Table 1.

It is noteworthy that the types of isolation layer of these two full-scale ballastless tracks are different. One is the geotextile isolation layer, and it is labeled as "standard assembly;" the other is a kind of rubber mat, and it is labeled as "subballasted mat". The main parameters of the materials of these two isolation layers are listed in Table 2.

At present, the leading concerned indicators of the geotextile materials are the tearing strength, the tensile strength, and so on. However, its compressive performance is rarely considered in practical engineering due to its thin thickness. For the rubber subballasted mat, its material properties are generally measured by the standard testing specimens, which can be guaranteed for the properties of the material itself $[19,20]$. However, the corresponding indicators of the rubber subballasted mat cannot be truly reflected only by the standard testing specimens due to its irregular shapes (Figure 6). The commonly used rubber subballasted mats usually have a thickness of $15 \sim 30 \mathrm{~mm}$, whereas their horizontal dimensions depend on the technique developed during the construction. Currently, there are various product specifications depending on the thickness and rigidity of the rubber mats. The subballasted mats are defined by their bedding modulus $\mathrm{C}_{\mathrm{d}}\left(\mathrm{N} / \mathrm{mm}^{3}\right)$; a series of rubber mats with a thickness of $27 \mathrm{~mm}$ and a design bedding modulus of $0.025 \mathrm{~N} / \mathrm{mm}^{3}$ are selected for further research in this work. The rubber subballasted mat used as an isolation layer has an irregular shape in this research, and it is composed of two layers: (i) a distribution layer to uniformly distribute loads; it is a piece of plate-like structure rubber, and its thickness is $10 \mathrm{~mm}$; (ii) an elastic layer to dampen loads; it is a set of evenly arranged circular truncated cone rubber structures, and its thickness is $17 \mathrm{~mm}$. The structure of the rubber subballast mat used in this work is shown in Figure 6.

2.2. Measuring Method and Sensors Arrangement. In this work, two kinds of measuring sensors are used to measure the interlayer vertical deformation of ballastless tracks, namely, embedment strain gauge and embedment jointmeter. Due to the differences in the measurement range of these measuring sensors, the embedment strain gauges are used to measure the interlayer deformation of ballastless track with geotextile isolation layer, and the embedment jointmeters are used to measure the interlayer deformation of ballastless track with rubber mat isolation layer.

Firstly, the lower ends of the measuring sensors are fixed on base plate upper steel bars, and they are kept vertical all the time during the pouring process of concrete base plate. Then, the measuring sensors are vertically passed through the isolation layer. Next, the upper ends of the measuring sensors are placed in a track slab, and they are consolidated with track slab steel bars. Finally, the concrete of track slab is poured so that the high-precision measurements of vertical displacements between layers are achieved. For ballastless track with rubber mat isolation layer, the vertical deformation at interlayers of the ballastless track is large enough to be measured directly by the embedment jointmeters. However, for ballastless track with geotextile isolation layer, the vertical deformation at interlayers is quite small to measure directly. Therefore, the strain at interlayers is measured by the embedment strain gauges, and then, the actual vertical deformations at interlayers can be deduced from the measured strain data. The layout of the embedment strain gauges and the embedment jointmeters is shown in Figure 7.

For the two full-scale ballastless tracks, six embedment strain gauges or six embedment jointmeters are arranged between isolation layers, respectively. Furthermore, both the arrangement and the nomenclature of the measuring sensors of these two full-scale ballastless tracks are the same. The arrangements of interlayer deformation measuring sensors are shown in Figure 8.

In addition, a series of steel strain gauges are attached on the upper and lower steel bars of the base plate and track slab, and a set of concrete strain gauges are arranged near the upper and lower surfaces of the base plate and track slab. 


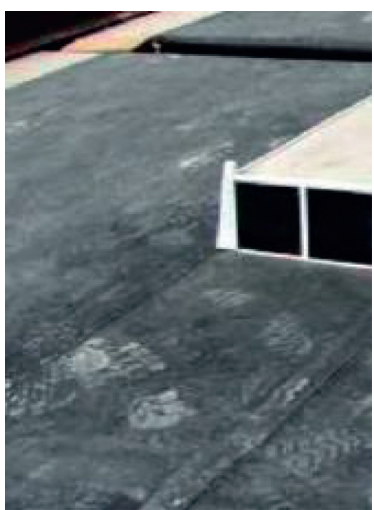

(a)

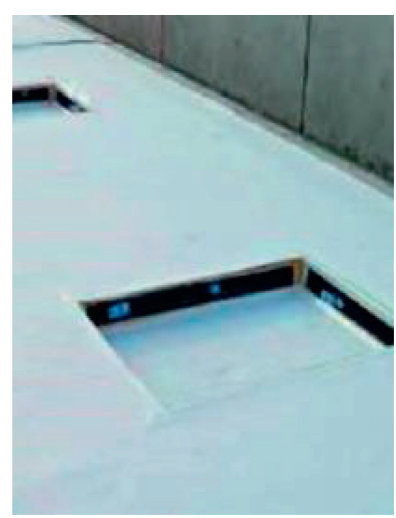

(b)

Figure 2: Commonly used isolation layers: (a) EPDM isolation layer; (b) geotextile isolation layer.

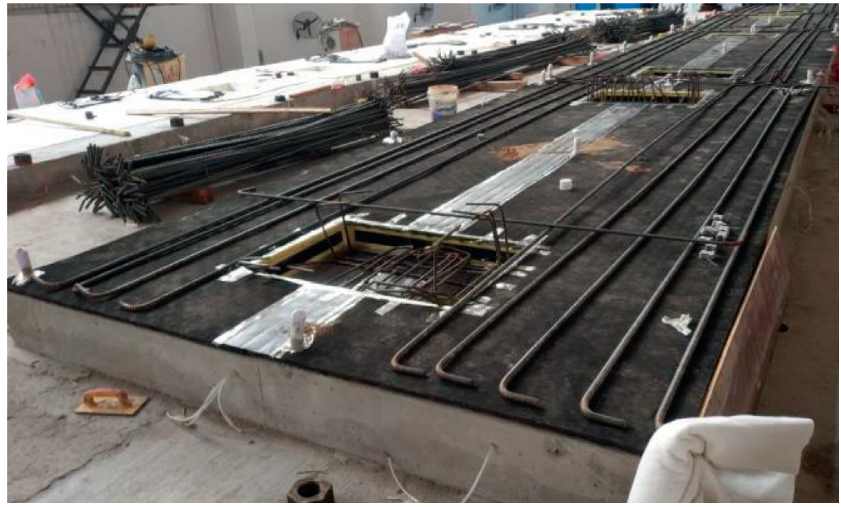

Figure 3: Rubber mat used as the isolation layer in ballastless track.

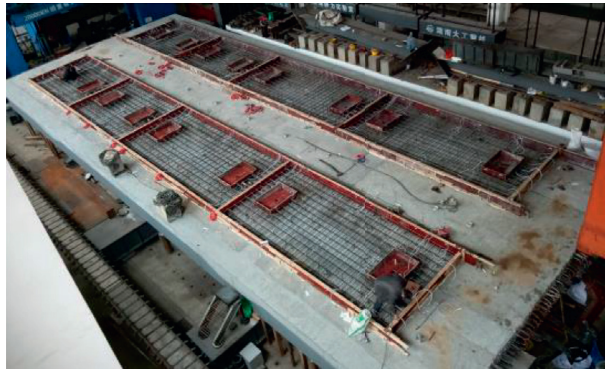

(a)

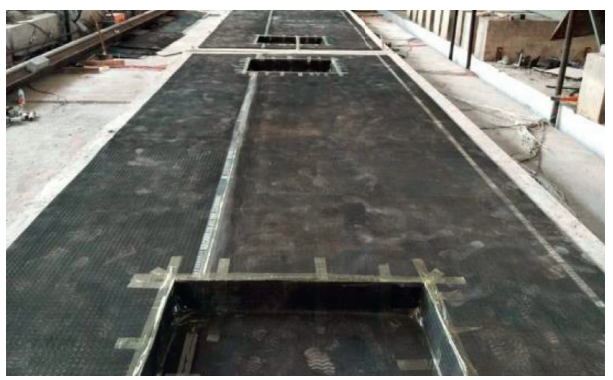

(c)

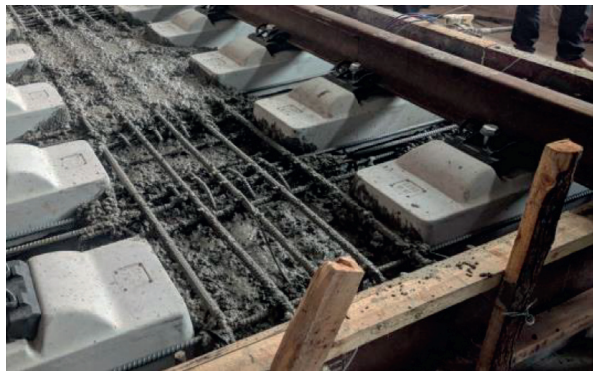

(b)

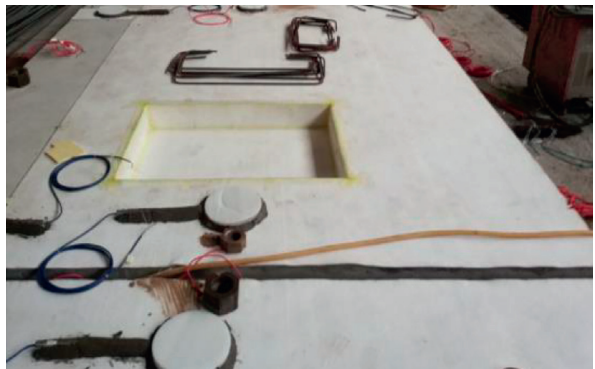

(d)

FIGURE 4: Test objects used in this work: (a) simply supported box girder; (b) ballastless tracks cast in place; (c) ballastless track with rubber mat isolation layer; (d) ballastless tracks with geotextile isolation layer. 


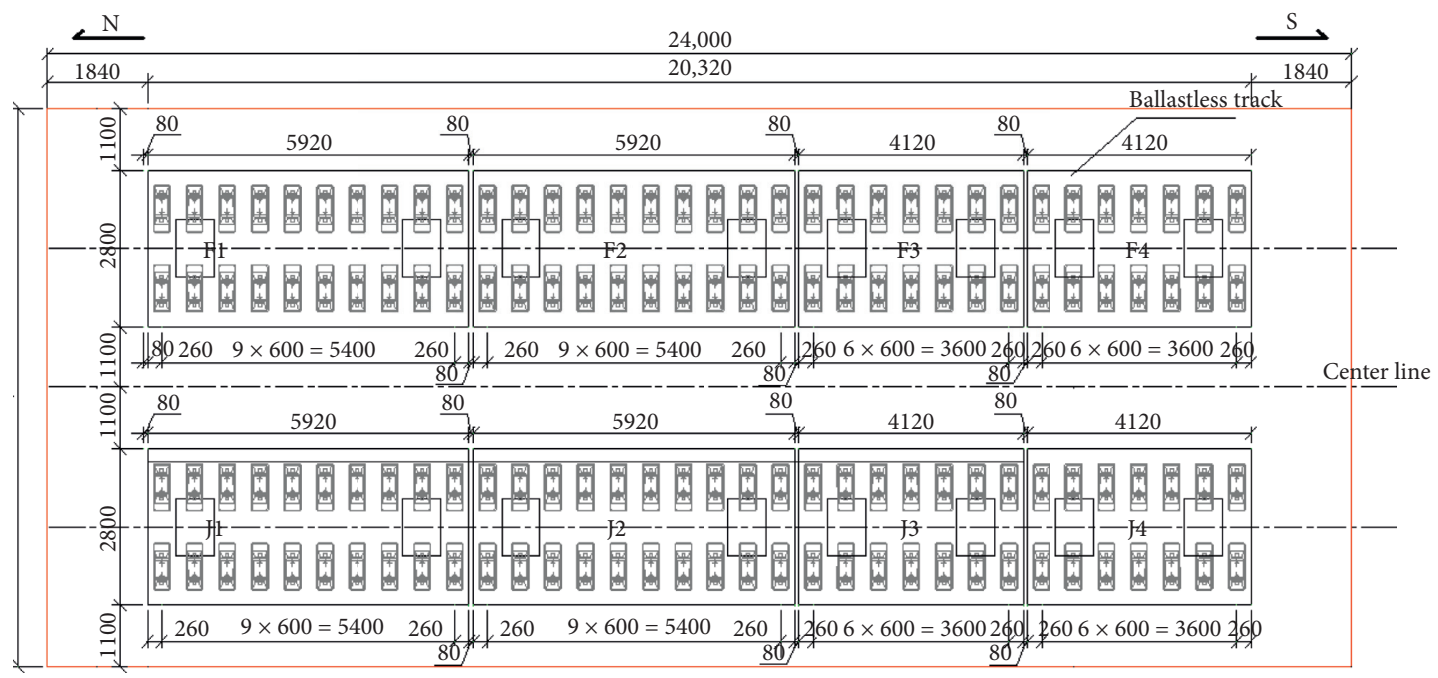

(a)

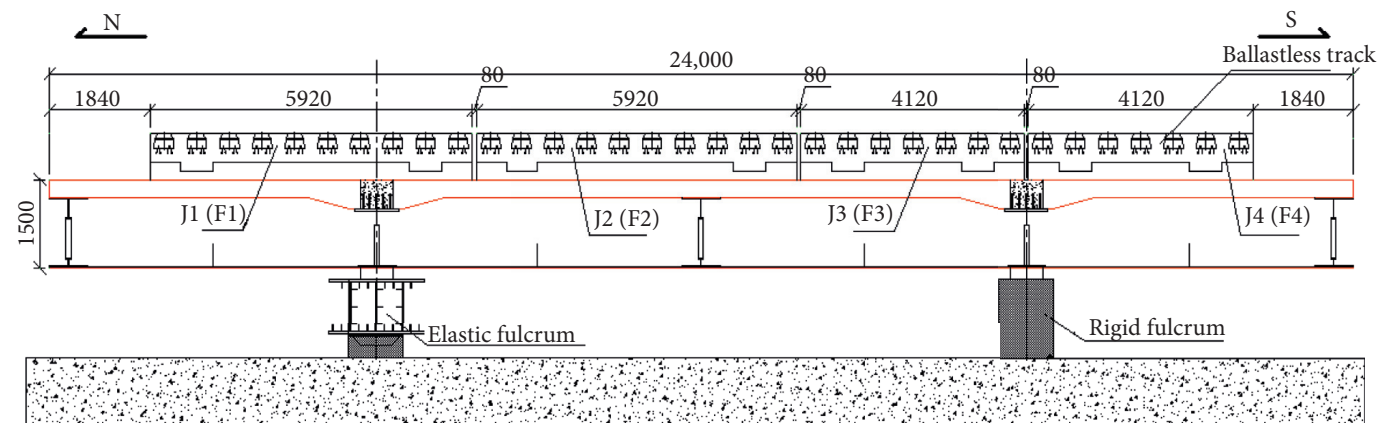

(b)

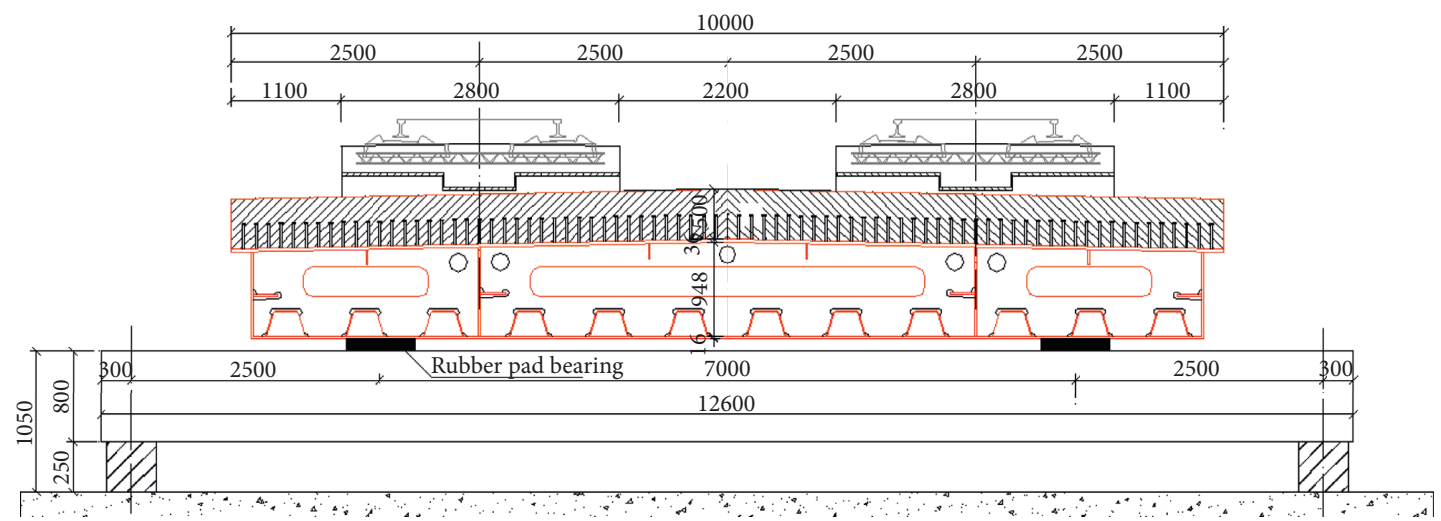

(c)

FIgUre 5: The simply supported box girder and ballastless tracks: (a) top view (unit: $\mathrm{mm}$ ); (b) side view (unit: mm); (c) front view (unit: $\mathrm{mm}$ ).

TABLE 1: The structural details of ballastless tracks used in this work.

\begin{tabular}{lcc}
\hline Component & Dimension $(\mathrm{mm})$ & Material or type \\
\hline Rail & & CHN60 \\
Fasteners & $5920 \times 2800 \times 260$ & WJ7-B constant resistance fasteners \\
Track slab & $5920 \times 2800 \times 27(4)$ & C40 concrete \\
Isolation layer & $5920 \times 2800 \times 240$ & Rubber (geotextile) \\
Base plate & C40 concrete \\
\hline
\end{tabular}


TABLE 2: The main parameters of two types of isolation layers in this work.

\begin{tabular}{|c|c|c|c|}
\hline No. & Index & Unit & Limits \\
\hline \multicolumn{4}{|c|}{ The material of geotextile isolation layer } \\
\hline 1 & Tensile strength & $\mathrm{kN} / \mathrm{m}$ & $\geq 48$ \\
\hline 2 & Elongation & $\%$ & $70 \pm 20$ \\
\hline 3 & Bursting strength & $\mathrm{kN}$ & $\geq 8.5$ \\
\hline 4 & Tearing strength by trapezoid method & $\mathrm{N}$ & $\geq 900$ \\
\hline 5 & Acid and alkali resistance & $\%$ & Retention rate $\geq 90$ \\
\hline 6 & Wear resistance & $\%$ & $\leq 25$ \\
\hline \multicolumn{4}{|c|}{ The material of subballasted mat isolation layer } \\
\hline 1 & Static stiffness & $\mathrm{MN} / \mathrm{m}$ & $3.0 \pm 0.5$ \\
\hline 2 & Determination of compression & $\%$ & $\leq 23$ \\
\hline 3 & Tensile strength & $\mathrm{MPa}$ & $\geq 3.0$ \\
\hline \multirow[t]{2}{*}{4} & Elongation & $\%$ & $\geq 150$ \\
\hline & Fatigue property & & \\
\hline \multirow[t]{2}{*}{5} & Appearance & \multicolumn{2}{|c|}{ No tearing or breakage occurs } \\
\hline & Residual deformation & $\mathrm{mm}$ & $\leq 1$ \\
\hline 6 & Water resistance & $\%$ & $\leq 1.0$ \\
\hline
\end{tabular}

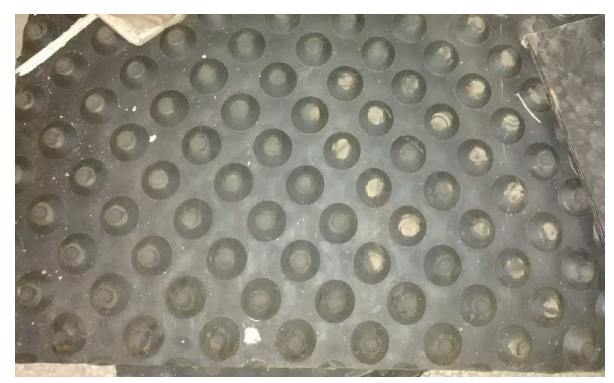

FIGURE 6: The structure of rubber mat used in this work.
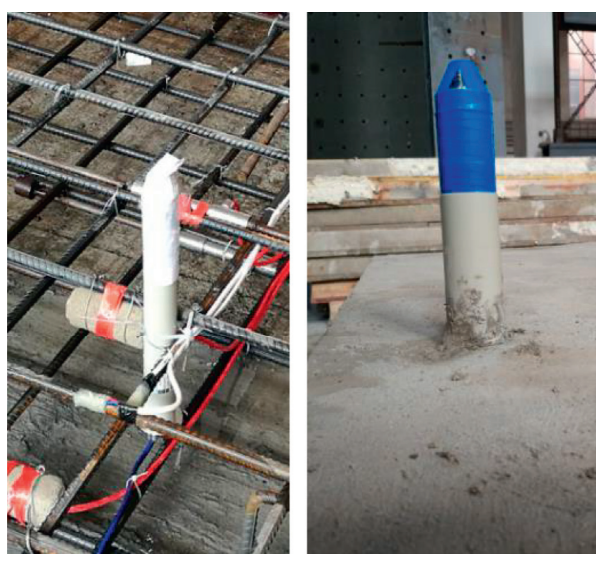

(a)
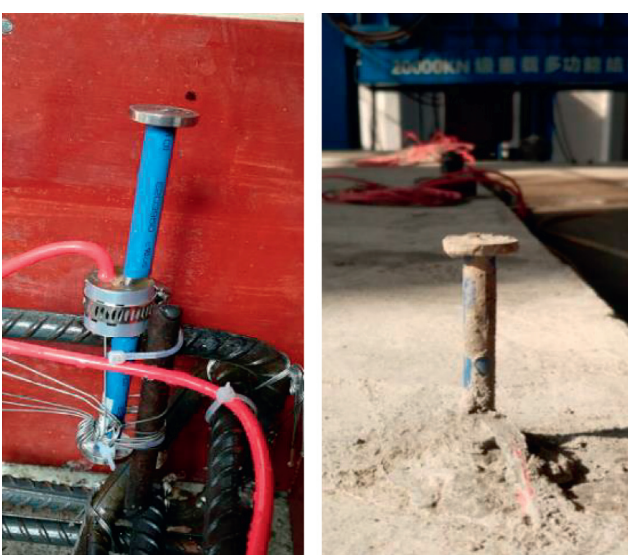

(b)

FIgURE 7: The layout of interlayer deformation measuring sensors: layout of the (a) embedment jointmeters and (b) embedment strain gauges.

Based on this, the stress levels of these two full-scale ballastless tracks with different isolation layers are tested, and the influences on the ballastless tracks can be judged by stress variations. The arrangements of these strain gauges are shown in Figure 9.
2.3. Test Procedure. After the maintenances of these two fullscale ballastless tracks are completed, a series of static loading tests are carried out. Moreover, the static loading tests are divided into two testing conditions: loading at the longitudinal end or the longitudinal center of the ballastless 


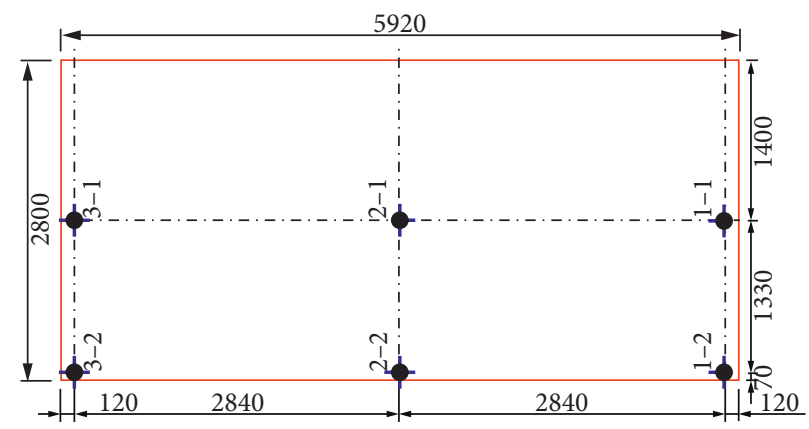

FIGURE 8: The arrangements of interlayer deformation measuring sensors (unit: $\mathrm{mm}$ ).

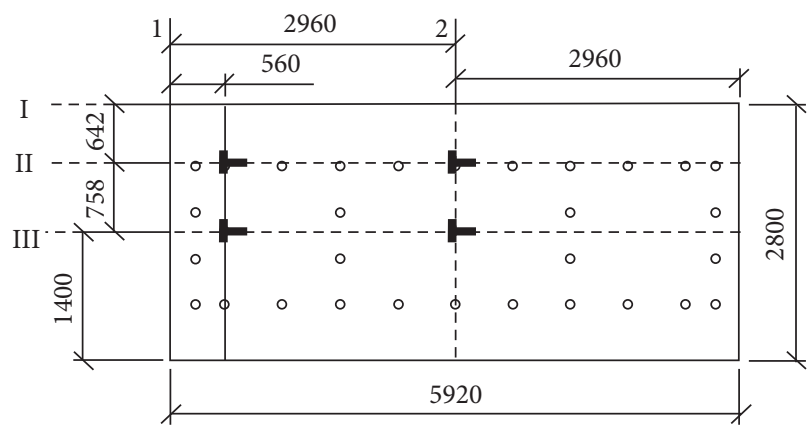

(a)

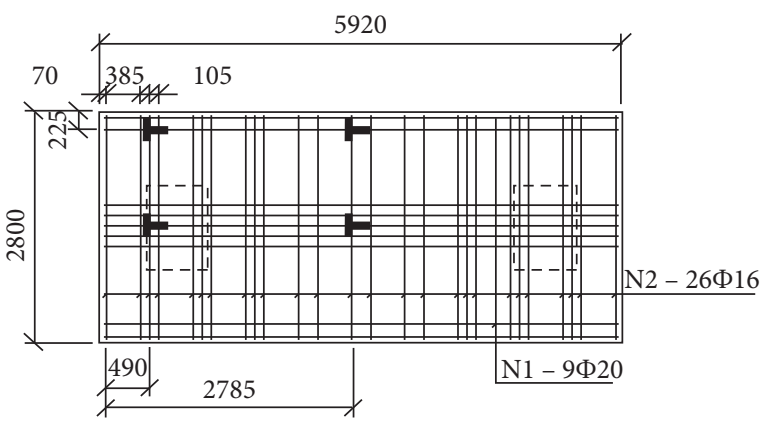

(b)

FIGURE 9: The arrangements of strain gauges (unit: $\mathrm{mm}$ ): the locations of the (a) concrete strain gauges and (b) steel strain gauges.

tracks, respectively. Three tests are conducted for each testing condition. The static loading is to simulate the axle load of a high-speed train, and the maximum testing load is $425 \mathrm{kN}$, which is 2.5 times of the axle load of a train $(170 \mathrm{kN})$. The whole static loading process is divided into ten stages, with an interval of 30 minutes between each stage. The static loading tests are repeated independently for three times of each testing condition. During the static loading test, the hydraulic jack is used to load in stages, and the load cell is arranged between the jack and the reaction frame to reflect the actual loading level in real time. Furthermore, the loading speed during the test does not exceed $1 \mathrm{kN} / \mathrm{s}$. After each loading stage is completed and stabilized for 30 minutes, the values of these measuring sensors are recorded. The static loading procedures and the loading devices are shown in Figure 10.

\section{Test Results}

3.1. Stress Level of the Ballastless Tracks. The stress values of each component of the ballastless tracks under different loading conditions are recorded separately. The stress distributions of the ballastless tracks are very simple under static loading, and the most unfavorable stress appears at loading positions. In detail, the maximum stress of each component among the testing results is summarized, as shown in Tables 3 and 4.

As shown in above Tables 3 and 4, under these two static test loading conditions, the stress levels of each component of the two full-scale ballastless tracks are very low. The stress level of track slab with rubber mat isolation layer is slightly higher than that with geotextile isolation layer. However, for the concrete base plate, the stress variation law is precisely opposite to that of track slab due to the different arrangements of isolation layers. Under static load, the local compressive deformations of rubber mat isolation layer are more significant than that of geotextile isolation layer. As a result, the track slab above the rubber mat isolation layer is undergoing large bending deformations. Moreover, the bending deformations lead to different stress distributions of ballastless tracks with different isolation layers. Fortunately, ballastless track generally consists of reinforced concrete structures or prestressed reinforced concrete structures, its material strength is high, and it has a particular ability to resist cracking. A little change in stress of ballastless tracks caused by the arrangement of rubber mat isolation layers will not have a significant impact on ballastless tracks, and the structural safety of ballastless tracks can be guaranteed.

3.2. Deformation Behaviors of the Ballastless Tracks. The interlayer deformation of ballastless track not only affects the smoothness of high-speed railway but also affects the durability of ballastless tracks. In this work, two static loading conditions are carried out on full-scale ballastless tracks with geotextile isolation layers or rubber mat isolation layers to research the interlayer deformation characteristics. The test results of the two full-scale ballastless tracks under these two static test loading conditions are summarized and analyzed as follows. 


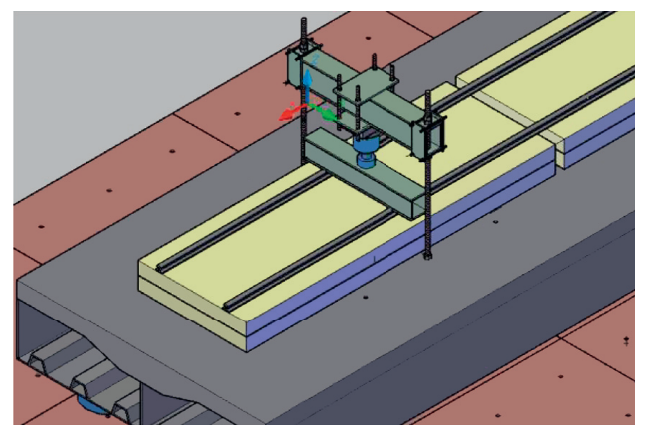

(a)

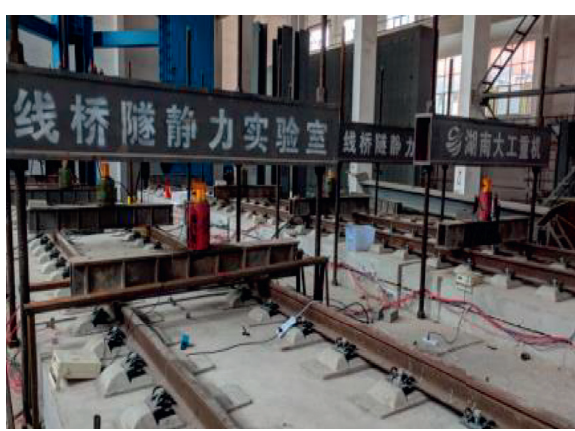

(b)

FIgURE 10: The static loading test: (a) static loading devices; (b) static loading procedure.

TABLE 3: The maximum values of concrete stress.

\begin{tabular}{|c|c|c|c|c|c|}
\hline \multirow[b]{2}{*}{$\begin{array}{l}\text { Types of the } \\
\text { ballastless tracks }\end{array}$} & \multirow[b]{2}{*}{ Components } & \multicolumn{2}{|c|}{ Loading at the slab center } & \multicolumn{2}{|c|}{ Loading at the slab end } \\
\hline & & $\begin{array}{l}\text { Longitudinal } \\
\text { stress (MPa) }\end{array}$ & $\begin{array}{c}\text { Transverse stress } \\
(\mathrm{MPa})\end{array}$ & $\begin{array}{l}\text { Longitudinal } \\
\text { stress }(\mathrm{MPa})\end{array}$ & $\begin{array}{c}\text { Transverse } \\
\text { stress (MPa) }\end{array}$ \\
\hline \multirow{4}{*}{ Standard assembly } & Top of track slab & -0.65 & -0.55 & 0.33 & 0.26 \\
\hline & Bottom of track slab & -0.98 & -0.87 & -0.65 & -0.64 \\
\hline & Top of base plate & -0.65 & -0.49 & -0.92 & -0.81 \\
\hline & Bottom of base plate & -0.40 & -0.46 & -0.56 & -0.42 \\
\hline \multirow{4}{*}{ Subballasted mat } & Top of track slab & 1.60 & 1.72 & 0.98 & 0.90 \\
\hline & Bottom of track slab & -1.30 & -1.18 & -1.63 & -1.67 \\
\hline & Top of base plate & -0.52 & -0.62 & -0.74 & -0.92 \\
\hline & Bottom of base plate & -0.33 & -0.34 & -0.52 & -0.54 \\
\hline
\end{tabular}

TABle 4: The maximum values of steel stress.

\begin{tabular}{|c|c|c|c|c|c|}
\hline \multirow{2}{*}{$\begin{array}{l}\text { Types of the ballastless } \\
\text { tracks }\end{array}$} & \multirow[b]{2}{*}{ Components } & \multicolumn{2}{|c|}{ Loading at the slab center } & \multicolumn{2}{|c|}{ Loading at the slab end } \\
\hline & & $\begin{array}{l}\text { Longitudinal stress } \\
(\mathrm{MPa})\end{array}$ & $\begin{array}{c}\text { Transverse stress } \\
(\mathrm{MPa})\end{array}$ & $\begin{array}{c}\text { Longtudinal stress } \\
(\mathrm{MPa})\end{array}$ & $\begin{array}{c}\text { Transverse } \\
\text { stress (MPa) }\end{array}$ \\
\hline \multirow{4}{*}{ Standard assembly } & Top of track slab & 4.00 & 3.02 & 3.00 & 1.96 \\
\hline & $\begin{array}{c}\text { Bottom of track } \\
\text { slab }\end{array}$ & -3.20 & -2.20 & -2.00 & -2.60 \\
\hline & Top of base plate & -4.60 & -3.50 & -6.40 & -5.80 \\
\hline & $\begin{array}{c}\text { Bottom of base } \\
\text { plate }\end{array}$ & -2.60 & -2.20 & -4.75 & -4.25 \\
\hline \multirow{4}{*}{ Subballasted mat } & Top of track slab & 12.00 & 10.00 & 12.00 & 11.10 \\
\hline & $\begin{array}{c}\text { Bottom of track } \\
\text { slab }\end{array}$ & -12.00 & -10.20 & -16.00 & -14.90 \\
\hline & Top of base plate & -5.00 & -3.80 & -6.70 & -6.30 \\
\hline & $\begin{array}{c}\text { Bottom of base } \\
\text { plate }\end{array}$ & -2.46 & -2.55 & -3.75 & -3.54 \\
\hline
\end{tabular}

Condition 1. static loading at longitudinal end of ballastless tracks.

There is a static loading at longitudinal end of ballastless tracks, which is next to sensor 3-1 and 3-2. The test results of each measuring sensor on the two full-scale ballastless tracks are shown in Figure 11, in which negative values represent compressive deformations at interlayers and positive values represent tensile deformations at interlayers.

Figure 11 shows the interlayer deformations of ballastless track with geotextile isolation layers or rubber mat isolation layers under static loading at longitudinal end of track slab.
The interlayer deformations of these two full-scale ballastless tracks at loading position are large, while those of the ballastless tracks far from the loading position are small. Besides, the interlayer deformations of these two ballastless tracks increase linearly with the increase in the static loadings. For ballastless track with geotextile isolation layer, the interlayer deformation is quite small, which is only $1 / 10$ of the interlayer deformation of ballastless track with rubber mat isolation layer. More importantly, the longitudinal edge of the track slab is more prone to warp. Furthermore, for ballastless track with rubber mat isolation layer, with the 

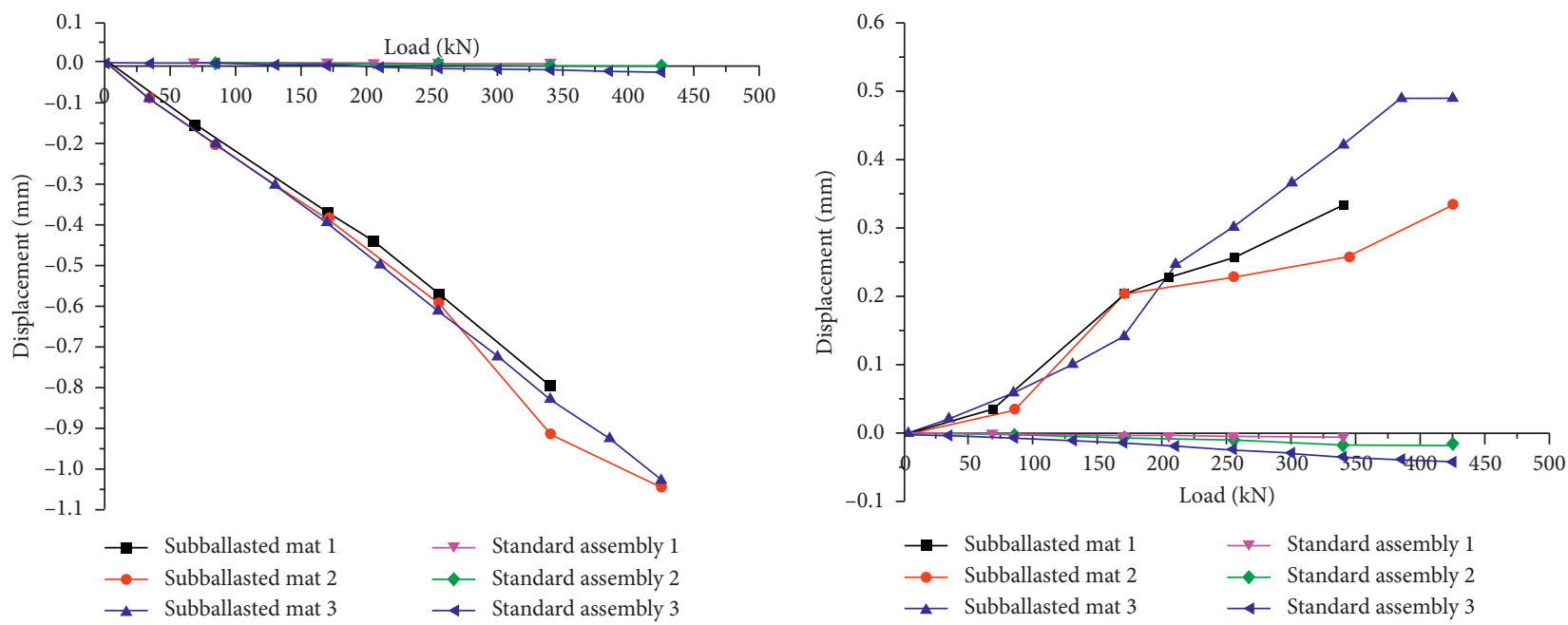

(a)
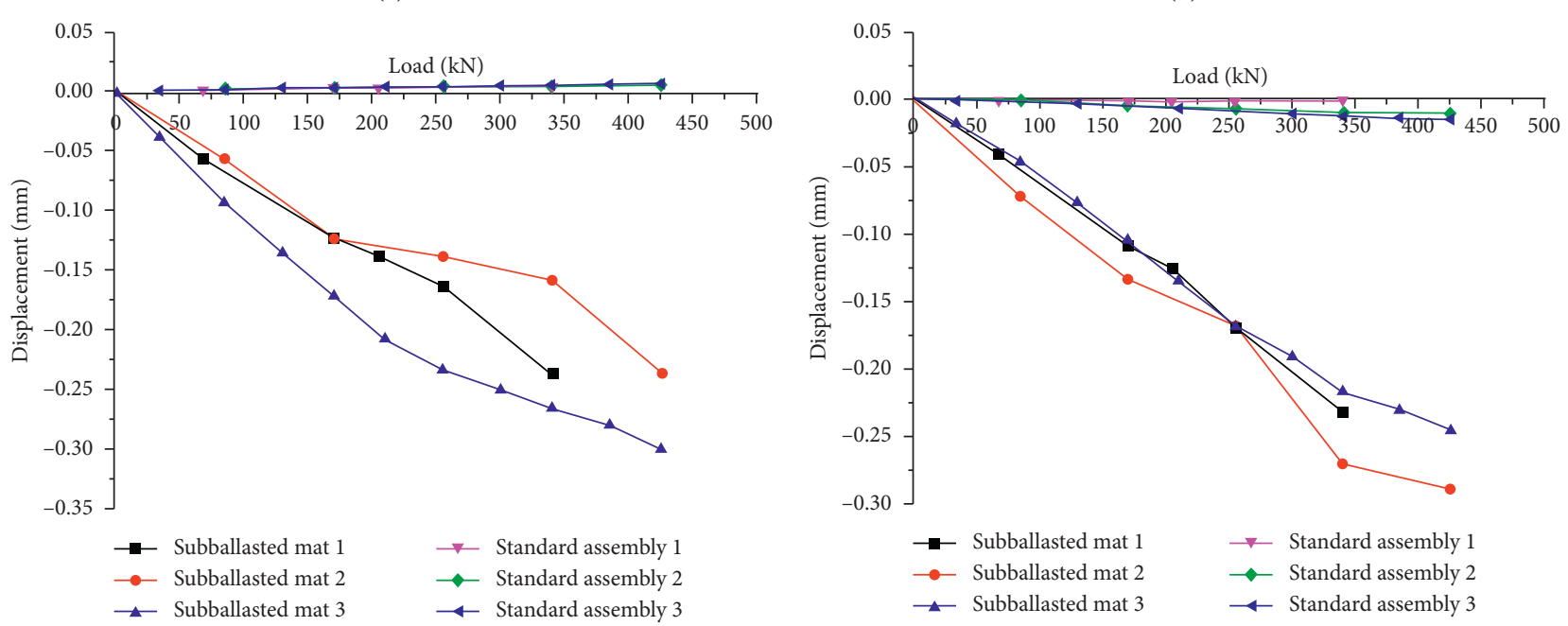

(c)

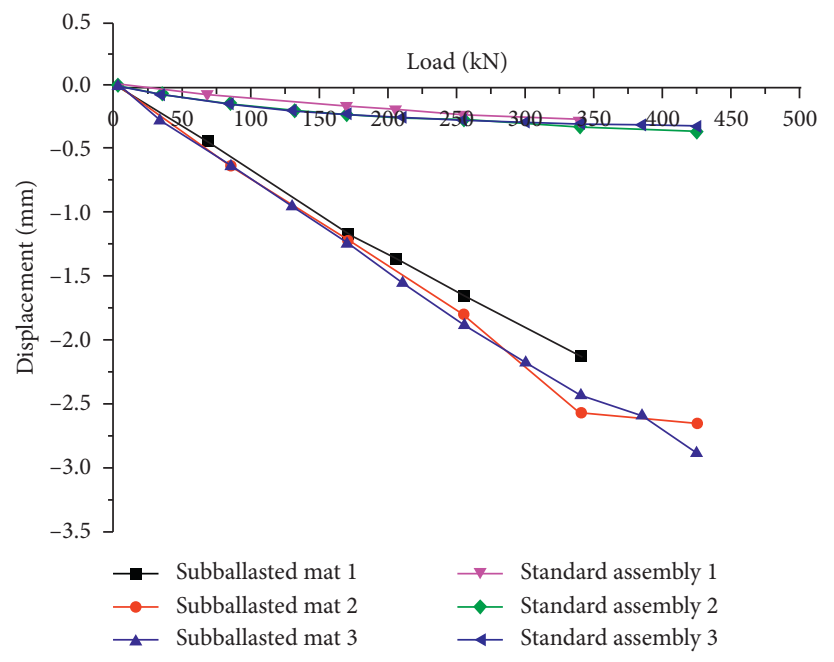

(e)

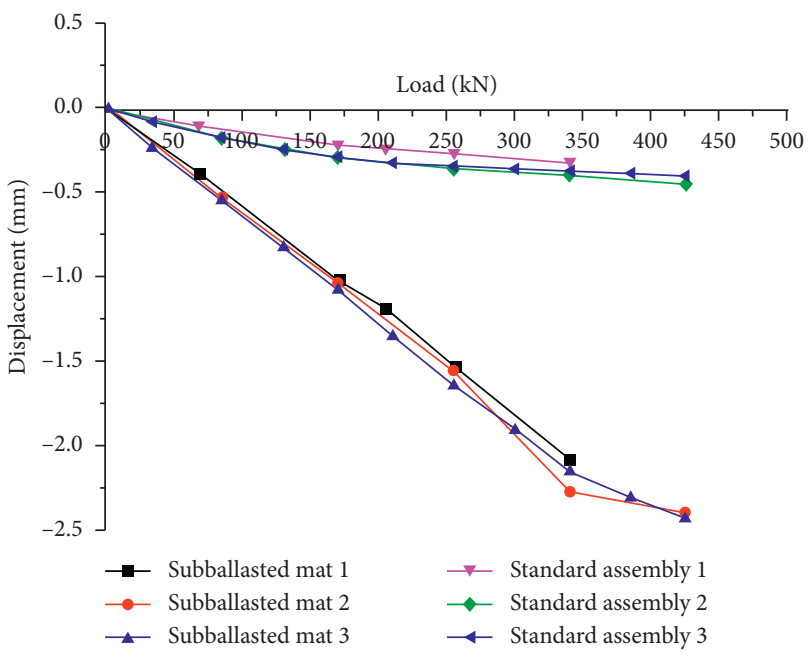

(f)

Figure 11: Interlayer deformations of the ballastless tracks loading at the slab end: (a) $1-1$; (b) $1-2$; (c) $2-1$; (d) 2-2; (e) 3-1; (f) 3-2. 
increase in static loading, tensile deformations in thickness direction of isolation layer tend to form at the other longitudinal end of track slab which is far from the loading position.

Condition 2. static loading at longitudinal center of ballastless tracks.

For the two full-scale ballastless tracks with rubber mat isolation layer or geotextile isolation layer, the static loading test is carried out at longitudinal center of ballastless tracks, which is near sensor 2-1 and 2-2. The deformation results of measuring sensors are shown in Figure 12.

From Figure 12, the interlayer deformations of ballastless tracks increase linearly with the increase in static loadings. Besides, the deformations of geotextile isolation layers are much small than those of rubber mat isolation layers, and it is hard to judge whether there are gaps or voids formation at interlayers of ballastless track with geotextile isolation layer due to its almost negligible compressive deformations. The rubber mat isolation layer is still in the liner-elastic state, and the deformation characteristics of rubber mat perform well. However, for ballastless track with rubber mat isolation layers, with the increase in static loading, tensile deformation occurred at interlayers of the end of ballastless track which is far from loading position. Whether gaps and voids can be formed or not is related to the precompression of rubber mat under deadweight of its upper structures, which is further analyzed in following sections.

\section{Discussion}

4.1. Deformation Characteristics of Ballastless Tracks. Concrete base plate is connected with bridge deck by embedded steel bars. The connection between the base plate and the bridge deck is firm and can deform together. However, track slab is formed by pouring concrete directly onto the isolation layer above base plate, and there is no binding force between track slab and base plate, which leads to deformation inconsistency between the two layers, such as gaps and voids.

Without considering the deformation of isolation layer, the deformation characteristics of each component of the ballastless track are deduced as follows.

The deflection $v(x)$, rotation $\theta(x)$, and curvature $\rho(x)$ of the main bridge or the ballastless tracks can be expressed as follows:

$$
\begin{aligned}
v(x), \theta(x) & =v^{\prime}(x), \\
\frac{1}{\rho(x)} & =v^{\prime \prime}(x) .
\end{aligned}
$$

It can be considered that the base plate and the bridge deck are well connected, and the deformation between the base plate and the bridge deck can be coordinated. That is to say,

$$
\begin{gathered}
v_{g}(x)=v_{b}(x), \\
v_{g}^{\prime}(x)=v_{b}^{\prime}(x), \\
v_{g}^{\prime \prime}(x)=v_{b}^{\prime \prime}(x) .
\end{gathered}
$$

In Formula (2), $g$ and $b$ are used to represent the main bridge and the concrete base plate, respectively.

The deformation of the concrete base plate is consistent with that of the main girder of the bridge, and its deflection equilibrium equation can be expressed as

$$
E_{g} I_{g} v_{g}^{\prime \prime}(x)=E_{b} I_{b} v_{b}^{\prime \prime}(x)=M_{g}(x)
$$

The track slab and the concrete base plate are separated entirely by the isolation layers. The deflection equilibrium equation of the track slab can be expressed as

$$
E_{s} I_{s} v_{s}^{\prime \prime}(x)=M_{s}(x) .
$$

In Formula (4), $s$ is used to represent the track slab.

Furthermore, the ballastless tracks laid on bridges are usually discontinuous, and there is a crack at the end of the track slab of a ballastless track, where

$$
M_{s}\left(x_{j}\right) \equiv 0 \text {. }
$$

In Formula (5), $x_{j}$ is the position of the crack.

However,

$$
M_{b}\left(x_{j}\right) \neq 0
$$

Considering the bending stiffness of the track slab is $0<E_{s} I_{s} \ll E_{g} I_{g}, E_{s} I_{s}$ cannot be ignored; that is to say, $E_{s} I_{s} \neq 0$. Because $E_{s} I_{s} v_{s}^{\prime \prime}\left(x_{j}\right)=M_{s}\left(x_{j}\right) \equiv 0$, for the track slab, $v_{s}^{\prime \prime}\left(x_{j}\right) \equiv 0$ certainly.

The deflection of the bridge is a continuous curve, and the curvature equation of the bridge is a continuous function or a piecewise continuous function. Therefore, for the main bridge and the base plate, $E_{g} I_{g^{\prime}} v_{g}^{\prime \prime}\left(x_{j}\right)=$ $E_{b} I_{b} v_{b}^{\prime \prime}\left(x_{j}\right)=M_{g^{\prime \prime}}\left(x_{j}\right) \neq 0$, and then, $v_{g}^{\prime \prime}\left(x_{j}\right) \neq 0, v_{b}^{\prime \prime}\left(x_{j}\right) \neq 0$. As a result, $v_{s}^{\prime \prime}\left(x_{j}\right) \neq v_{g}^{\prime \prime}\left(x_{j}\right)$; besides, $v_{s}\left(x_{j}\right) \neq v_{g}\left(x_{j}\right)$, $v_{s}^{\prime}\left(x_{j}\right) \neq v_{g}^{\prime}\left(x_{j}\right)$.

In all, the deformation of track slab laid on bridges is not exactly the same as that of main bridge. For ballastless tracks laid on bridges, without considering the compressive deformations of isolation layers, the coordination of the deformations between track slab and main bridge cannot be achieved. That is to say, it is inevitable that there will be gaps and voids formation between track slab and concrete base plate for the ballastless track with geotextile isolation layers.

4.2. Deformations at Interlayers of Ballastless Tracks. The reasonable arrangement of isolation layer in ballastless track is an effective way to avoid deformation inconsistency between track slab and main bridge. During the operation process, interlayer tensile deformations under routine service condition do not exceed the precompressions of isolation layers, and the interlayers of ballastless tracks are compactly filled with isolation layers, so as to improve the stress state of ballastless tracks, slow down the deterioration of ballastless tracks, and improve the deformation behaviors of ballastless tracks. For geotextiles or EPDM isolation layers which are commonly used in ballastless tracks on railroad bed, their thickness is very thin (less than $4 \mathrm{~mm}$ ), and the compressive deformations of these isolation layers can be nearly neglected under the deadweight of its upper 


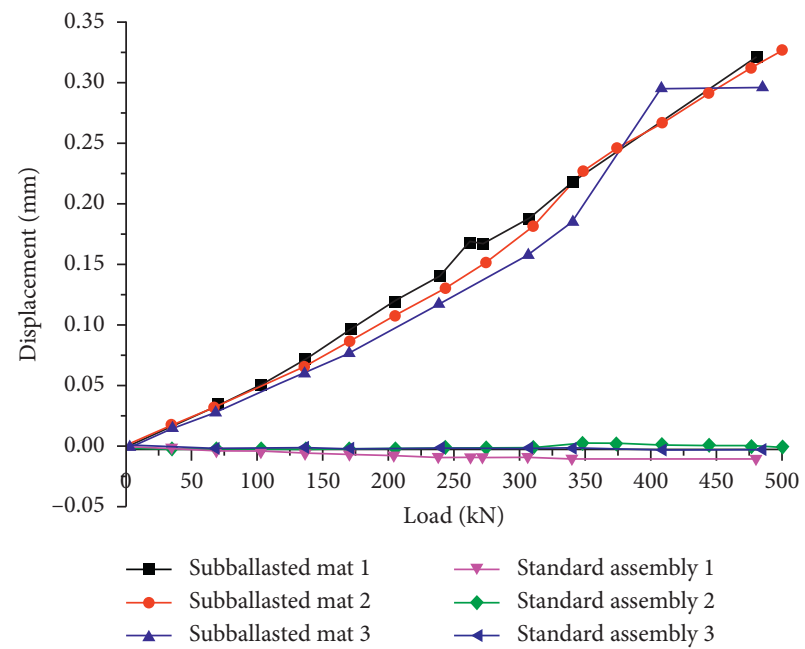

(a)

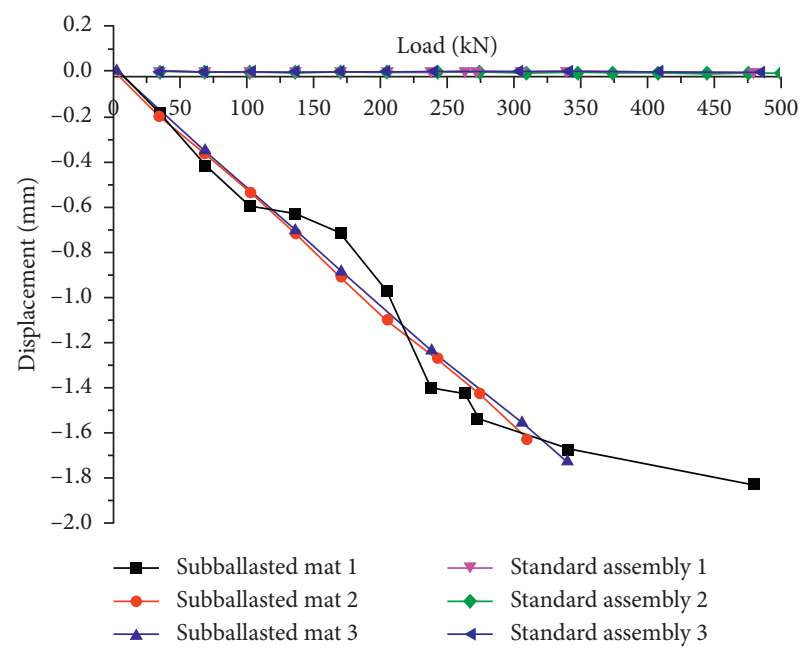

(c)

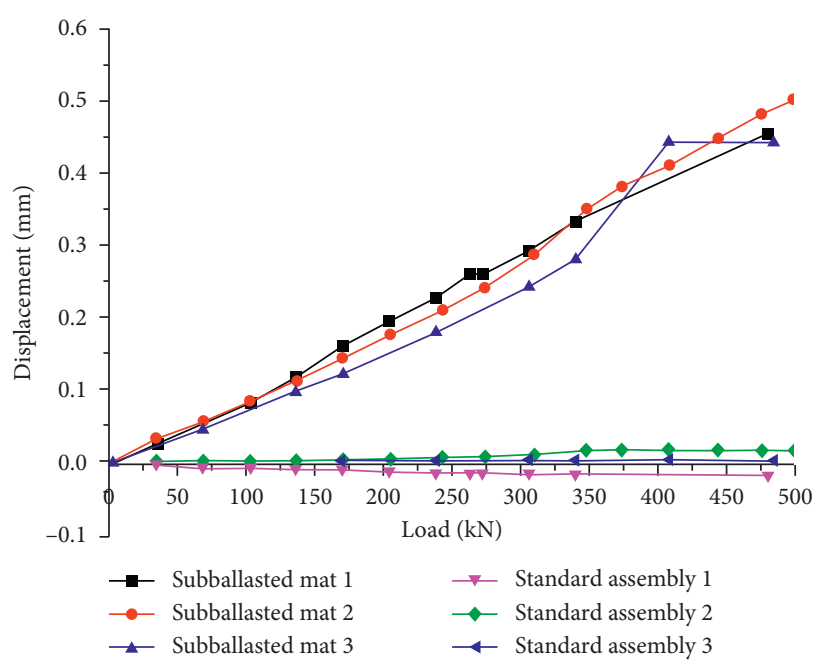

(b)

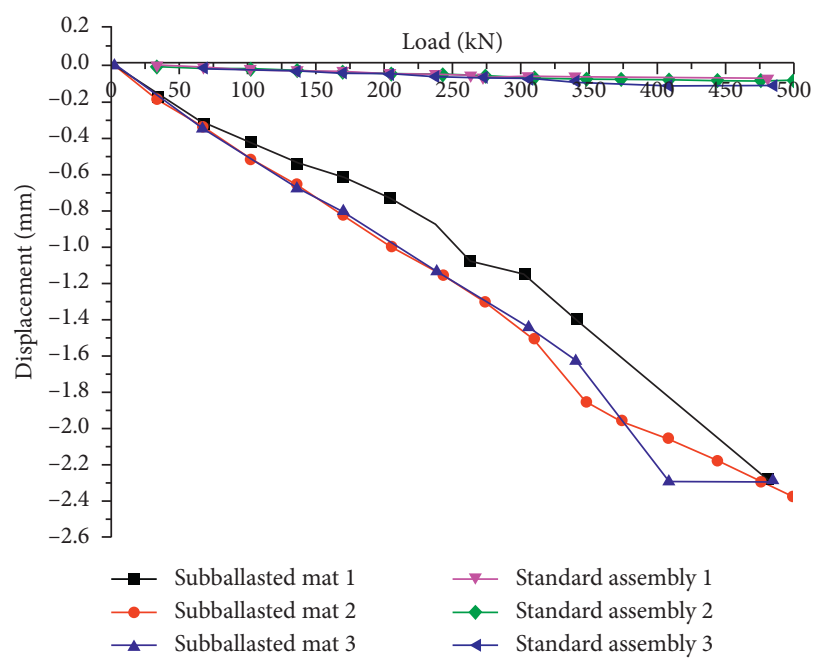

(d)

Figure 12: Interlayer deformations of the ballastless tracks loading at the slab center: (a) 1-1; (b) 1-2; (c) 2-1; (d) 2-2.

structures. When ballastless track with these isolation layers is laid on rigid foundation such as bridge structures, it is highly that there will be gaps and voids formation between track slab and base plate. For the rubber mat used as isolation layer, its thicknesses are always large $(15 \sim 30 \mathrm{~mm})$, and compressive stiffness can be accurately obtained according to its bedding modulus. It can be considered that the rubber mat used as isolation layer is in a state of uniform compression, and its precompression is about $0.4 \mathrm{~mm}$ under deadweight of upper structures.

For high-speed trains in China, the standard train axle load is $170 \mathrm{kN}$, and the control load of a train axle load acting on substructures is $255 \mathrm{kN}$ ( 1.5 times of $170 \mathrm{kN}$ ). Under the action of the above load levels, the deformations of ballastless tracks are significant. It is considered that these deformations are essential indicators for evaluating the impact on operation of high-speed trains. Thus, the maximum compressive and tensile deformations at interlayers of ballastless tracks are listed in Table 5 .
In Table 5, under the standard axle load of $255 \mathrm{kN}$, the maximum compressive and tensile deformations at interlayers of ballastless track with rubber mat isolation layer are $1.70 \mathrm{~mm}$ and $0.23 \mathrm{~mm}$, respectively. The maximum tensile deformation does not exceed the precompression $(0.4 \mathrm{~mm})$ of rubber mat isolation layer under deadweight of its upper structures. Besides, the maximum compressive deformation at interlayers also meets the limit of track irregularity $(2 \mathrm{~mm})$ [9]. As a result, there will be no gap and void formed at interlayers of ballastless track with rubber mat isolation layer, and this allows for an increase in durability and quality of ballastless tracks. At the same time, the arrangement of rubber mat isolation layer will not have a significant impact on operation of high-speed trains. For ballastless track with geotextile isolation layer, the maximum compressive and tensile deformations at interlayers are tiny. Not surprisingly, the test data of the compressive and tensile deformations at interlayers are discrete. 
TABLE 5: The maximum deformations at interlayers.

\begin{tabular}{|c|c|c|c|c|c|c|}
\hline \multirow[t]{2}{*}{ Load conditions } & \multirow[b]{2}{*}{ Load values $(\mathrm{kN})$} & \multicolumn{2}{|c|}{$\begin{array}{c}\text { Loading at slab } \\
\text { end }\end{array}$} & \multicolumn{2}{|c|}{$\begin{array}{c}\text { Loading at slab } \\
\text { center }\end{array}$} & \multirow[t]{2}{*}{ Limits [9] (mm) } \\
\hline & & 170 & 255 & 170 & 255 & \\
\hline \multirow{2}{*}{ Standard assembly } & Maximum tensile deformations (mm) & 0.003 & 0.004 & 0.001 & 0.002 & $\leq 0$ \\
\hline & Maximum compressive deformations (mm) & 0.25 & 0.35 & 0.03 & 0.05 & $\leq 2$ \\
\hline \multirow{2}{*}{ Subballasted mat } & Maximum tensile deformations (mm) & 0.17 & 0.23 & 0.15 & 0.22 & $\leq 0.4$ \\
\hline & Maximum compressive deformations ( $\mathrm{mm}$ ) & 1.18 & 1.70 & 0.90 & 1.25 & $\leq 2$ \\
\hline
\end{tabular}

\section{Conclusions}

The reasonable arrangement of isolation layer can improve the deformation behaviors of ballastless tracks laid on bridges. Rubber mats are applied in ballastless tracks laid on high-speed railway bridges as isolation layers to realize interlayer isolation and deformation coordination. The static loading tests of two full-scale ballastless tracks with rubber mat isolation layer or geotextile isolation layer have been carried out. The main conclusions are as follows:

(1) For the slab ballastless tracks laid on rigid foundation such as bridges, without considering the precompressions of isolation layer, gaps and voids can be formed at interlayers of the ballastless tracks.

(2) The application of rubber mats reduces the possibility of gaps and voids formed at interlayers of ballastless tracks. Meanwhile, the application of rubber mat has a slight effect on ballastless track stress distribution, but the safety and reliability of ballastless tracks can be guaranteed.

(3) Under the routine service condition, the rubber mats are still in elastic working state, and the interlayer deformations of ballastless tracks perform well. The tensile and compressive deformations of rubber mat isolation layers are more evident than those of geotextile isolation layers, which still meet the requirements of the specifications concerned.

\section{Data Availability}

The data used to support the findings of this study are available from the corresponding author upon request.

\section{Conflicts of Interest}

The authors declare that there are no conflicts of interest.

\section{Acknowledgments}

This research was supported by the Fundamental Research Funds for the Central Universities of Central South University (2017zzts155). The authors would like to thank the financial sponsorship provided by the China Railway Corporation (2015G001-G).

\section{References}

[1] Z. Yu, Y. Xie, Z. Shan, and X. Li, "Fatigue performance of CRTS III slab ballastless track structure un-der High-speed train load based on concrete fatigue damage constitu-tive law," Journal of Advanced Concrete Technology, vol. 16, no. 5, pp. 233-249, 2018.

[2] M. Sol-Sánchez, F. Moreno-Navarro, and M. C. RubioGámez, "The use of elastic elements in railway tracks: a state of the art review," Construction and Building Materials, vol. 75, pp. 293-305, 2015.

[3] M. Sol-Sánchez, L. Pirozzolo, F. Moreno-Navarro, and M. C. Rubio-Gámez, "A study into the mechanical performance of different configurations for the railway track section: a laboratory approach," Engineering Structures, vol. 119, pp. 13-23, 2016.

[4] X. W. Sheng, W. Q. Zheng, and J. X. Wu, "Influence of local deformation mode of cable-stayed bridge on unballasted tracks: experimental research," Advances in Civil Engineering, vol. 2020, pp. 1-10, 2020.

[5] W. Zheng, X. Sheng, Z. Zhu, T. Luo, and Z. Liu, "Experimental study on vibration characteristics of unit-plate ballastless track systems laid on long-span bridges using full-scale test rigs," Sensors, vol. 20, no. 6, p. 1744, 2020.

[6] S. K. Navaratnarajah and B. Indraratna, "Use of rubber mats to improve the deformation and degradation behavior of rail ballast under cyclic loading," Journal of Geotechnical and Geoenvironmental Engineering, vol. 143, pp. 685-697, 2017.

[7] X. Sheng, W. Zheng, and Z. Zhu, "Mechanical behaviors and fatigue performances of ballastless tracks laid on long-span cable-stayed bridges with different arrangements," Sensors, vol. 19, no. 19, p. 4195, 2019.

[8] TJ/GW 114-2013, Temporary Technical Conditions of EPDM Elastic Buffer Cushion for CRTS III Plate Ballastless Track of High Speed Railway, TJ/GW 114-2013, Beijing, China, (in Chinese), 2013.

[9] TB 10621-2014, . Code for Design of High Speed Railway, TB 10621-2014, Beijing, China, (in Chinese), 2014.

[10] Y. L. Liu, X. M. Kong, Y. R. Zhang, and P. Y. Yan, "Static and dynamic mechanical properties of cement-asphalt composites," Journal of Materials in Civil Engineering, vol. 25, no. 10, pp. 1489-1497, 2013.

[11] M. Sol-Sánchez, F. Moreno-Navarro, and M. C. RubioGámez, "Viability analysis of deconstructed tires as material for rail pads in high-speed railways," Materials \& Design, vol. 64, pp. 407-414, 2014.

[12] X.-W. Sheng, W.-Q. Zheng, Z.-H. Zhu, T.-J. Luo, and Y.-H. Zheng, "Properties of rubber under-ballast mat used as ballastless track isolation layer in high-speed railway," Construction and Building Materials, vol. 240, p. 117822, 2020.

[13] B. Indraratna, Q. Sun, and A. Heitor, "Performance of rubber tire-confined capping layer under cyclic loading for railroad 
conditions," Journal of Material in Civil Engineering, vol. 30, pp. 2255-2263, 2018.

[14] S. Nimbalkar, B. Indraratna, S. K. Dash, and D. Christie, "Improved performance of railway ballast under impact loads using shock mats," Journal of Geotechnical and Geoenvironmental Engineering, vol. 138, no. 3, pp. 281-294, 2012.

[15] P. F. Teixeira, P. A. Ferreira, P.A. López, C. Casas, and A. Bachiller, "The use of bituminous subballast on future high-speed lines in Spain: structural design and economical impact," IJR International Journal of Railway, vol. 2, pp. 1-7, 2009.

[16] J. G. Rose and L. S. Bryson, "Hot mix asphalt railway trackbeds: trackbed materials, performance evaluations, and significant implications," in Proceedings of the International Conference on Perpetual Pavements, Columbus, OH, USA, May 2009.

[17] UIC Code 719-1. Recommendations for the Use of under Ballast Mats. UBM 1st ed. VII Way and Works: 2011.

[18] W. Zheng, X. Sheng, Z. Zhu, and H. He, "Experimental study on deformation characteristics of ballastless tracks under downward bending deformation of long-span cable-stayed bridge," Engineering Structures, vol. 210, p. 110363, 2020.

[19] C. E. Hanson and H. L. Singleton, "Performance of ballast mats on passenger railroads: measurement vs. projections," Journal of Sound and Vibration, vol. 293, no. 3-5, pp. 873-877, 2006.

[20] A. De O Lima, M. S. Dersch, Y. Qian, E. Tutumluer, and J. R. Edwards, "Laboratory fatigue performance of underballast mats under varying loads and support conditions," Proceedings of the Institution of Mechanical Engineers Part F: Journal of Rail and Rapid Transit, vol. 233, no. 16, pp. 606-613, 2018. 